\title{
Components of prism adaptation in terminal and concurrent exposure: Organization of the eye-hand coordination loop
}

\author{
GORDON M. REDDING \\ Illinois State University, Normal, Illinois \\ and \\ BENJAMIN WALLACE \\ Cleveland State University, Cleveland, Ohio
}

\begin{abstract}
In three experiments, aftereffect measures of visual-shift and proprioceptive-shift components and total shift in eye-hand coordination were obtained for prism exposure. In one condition the hand was visible for most of the sagittal pointing movement (concurrent exposure), whereas in the other condition only the fingertip was visible at the end of the movement (terminal exposure). Visual shift was greater than proprioceptive shift with terminal exposure and the reverse was true with concurrent exposure, except that proprioceptive shift tended to be greater in both exposure conditions when head movement was permitted. Total shift was not different from the sum of its components except when targets were present, in which case total shift tended to be greater than the sum. Proprioceptive aftereffects for the unexposed hand were small except when head movement was permitted and appeared to be related to changes in felt head position. Aftereffects for target pointing with the unexposed hand were not found to be related to visual shift. The results are discussed in terms of a view of the eye-hand coordination loop as a serial linkage of component eye-head and hand-head systems, with the locus of adaptation determined by the direction of the coordinative linkage between component systems.
\end{abstract}

The ability of the human organism to respond adaptively to optical transformations such as displacement or rotation of the visual field has been known since the end of the last century (e.g., Helmholtz, 1925; Stratton, 1896). Almost two decades of intense research, from about 1955 to 1975 , revealed the bewildering complexity of this adaptive response, including postural adjustments, simple motor-response learning, and perceptual changes in vision, proprioception, and audition (for a review, see Welch, 1978). Yet some organization is beginning to emerge. For instance, the total adaptive response to a particular exposure situation can usually be described in terms of local adaptive changes in a linear system (Howard, 1971,1982 ) and additive contributions from the various components of such a serially organized system (e.g., Hay \& Pick, 1966; Redding, 1978; Redding \& Wallace, 1976, 1978; Templeton, Howard, \& Wilkinson, 1974; Wallace, 1977; Wallace \& Redding, 1979; Welch, 1974; Welch, Choe, \& Heinrich, 1974; Wilkinson, 1971).

These findings suggest that prism adaptation can be understood as an artificial instance of the natural ability of

This research was supported in part by Grant 1-R03-MH34383 from the National Institute for Mental Health to the second author. Special thanks are due Mary Persanyi and Albert Borroni for assistance in data collection. Requests for reprints should be addressed to Gordon M. Redding, Department of Psychology, Illinois State University, Normal, IL 61761 . the perceptual-motor system to maintain spatial alignment among its various component systems (Craske, 1975; Redding, Clark, \& Wallace, 1985). The total perceptualmotor system can be conceptualized as consisting of several subsystems (e.g., eye-head, hand-shoulder, earneck, and foot-trunk), each with sensory and effector capacities and the capability of operation independent of other subsystems. Coordination of subsystems, however, requires that spatial information be "translated" from the spatial coordinates of one subsystem to those of another, and such spatial alignment is subject to a variety of natural perturbations (e.g., growth, pathology, and "drift"; Held \& Bossom, 1961; Robinson, 1976). Prism adaptation, then, can be considered an experimental example of the process that normally maintains subsystems in a state of cross-calibration, and prism adaptation research becomes a means of investigating the organization of the perceptualmotor system. For instance, variability in the locus of adaptation for different exposure tasks may indicate how coordinative linkages are established among subsystems of the total perceptual-motor system.

The viability of this view is illustrated by recent investigations (Redding et al., 1985; Redding \& Wallace, $1985 \mathrm{a}, 1985 \mathrm{~b})$ of prism adaptation during locomotion along hallways. This work suggests that locomotion per se is mediated by an eye-foot movement system utilizing optical flow information that is unaffected by optical dis- 
placement of the visual field. Adaptation to discordance among positional systems (eye-head, eye-hand, and earneck) seems to require that systems be directionally linked in such a way that one system serves as the source of guidance signals for another, with adaptation occurring in the guided system (Redding \& Wallace, 1985b, 1987). Moreover, limited central processing capacity (attention) is utilized in establishing and maintaining the directional linkages between discordant systems necessary for adaptation (Redding et al., 1985; Redding \& Wallace, 1985a).

The present investigation was intended to examine another common prism-adaptation task, pointing with the hand visible through displacing prisms (hand exposure). Of particular interest were conditions that seem to produce different loci for adaptation. It has generally been reported (e.g., Cohen, 1967; Freedman, 1968; Uhlarik \& Canon, 1971) that exposure with the hand visible throughout the movement (concurrent exposure) tends to produce more proprioceptive than visual adaptation, but restricting the subject's view to only the fingertip at the end of the movement (terminal exposure) tends to produce more visual than proprioceptive adaptation. ${ }^{1}$ An understanding of why terminal and concurrent exposure produce reversal in the relative magnitude of visual and proprioceptive adaptation might, therefore, inform us about the organization of the perceptual-motor system in eye-hand coordination tasks. However, this assumed differential effect of terminal versus concurrent exposure is based in part upon comparisons across experiments that differ in many respects. Thus, our goal in Experiment 1 was to provide a verification of the differential exposure effects with adequate controls for a number of possibly relevant variables.

Many of the studies showing differential effects of terminal versus concurrent exposure have not directly measured visual adaptation (but see Uhlarik \& Canon, 1971). Rather, visual adaptation has been assessed by the magnitude of intermanual transfer of adaptation in pointing at targets with the unexposed hand. Any difference in such transfer has been assumed to reflect a difference in visual adaptation (e.g., Choe \& Welch, 1974; Welch, 1978, p. 95). Thus, one of our goals in the present study was to provide a comparison between direct and transfer measures of visual shift. In addition, we obtained intermanual transfer measures without vision in an attempt to distinguish more clearly the visual component in measures of intermanual transfer. Previous studies of terminal versus concurrent exposure have also usually employed targets that were physically straight ahead but optically displaced (but see Freedman, 1968). Thus, the eyes could have assumed an asymmetric posture and at least part of the visual adaptation observed could consist in eye-muscle potentiation aftereffects (e.g., Ebenholtz, 1974, 1976; Ebenholtz \& Fisher, 1982) rather than mere central perceptual recalibration. ${ }^{2}$ In the present ixperiments, when targets were used they were physically displaced so as to minimize asymmetric eye posture. Some of the previous studies (e.g., Uhlarik \& Canon, 1971) measured adaptation with prisms in place (direct effects), rather than after- effects with the prisms removed. Thus, part of the obtained adaptation may have been due to conscious correction rather than perceptual adaptation. Aftereffects were measured in the present experiments to minimize the possibility of test contamination by application of a conscious rule acquired during exposure.

In addition to these control procedures, we manipulated several variables that might have been relevant for the differential effect of terminal versus concurrent exposure. Specifically, in Experiment 1 we examined the effect of exposure targets, in Experiment 2 we investigated head movement during exposure, and in Experiment 3 we compared results for exposed left and right hands.

\section{GENERAL METHOD}

\section{Subjects}

Right-handed undergraduate volunteers at Cleveland State University served as subjects in all experiments. All subjects had selfreported normal vision or vision corrected to normal by contact lenses. Apparatus restrictions prevented testing of people who wore glasses.

\section{Apparatus}

The apparatus used in all experiments was similar to that employed by Wallace (1978). Specifically, this structure consisted of a two-layer rectangular wooden box-like frame $(77 \mathrm{~cm}$ high, $62 \mathrm{~cm}$ wide, and $62 \mathrm{~cm}$ deep) open on the side facing the subject. When a subject placed his/her arm within the structure, on the lower layer, the arm was not visible. During test, the experimenter could note the position of the arm on the lower layer by determining its location along a $180^{\circ}$ arc, calibrated in $1^{\circ}$ increments. During exposure, placement of the subject's arm on the upper layer permitted the individual to perceive his/her arm movement. When a plywood cover located $12 \mathrm{~cm}$ directly above the second layer of the apparatus was in place, sight of the arm was restricted to the tip of the pointing finger at the terminus of an exposure response. When the cover was removed, the subject could see the arm for most of the normal range of a pointing response. All visible surfaces were homogeneously white, except for vertical black line targets $(.2 \times 8 \mathrm{~cm})$. Attached to the apparatus was a Marietta Instruments combination head- and chinrest. Subjects wore welder's goggles with a Risley prism mounted in each eyepiece. The prisms could be set to produce lateral displacement of the optic array varying from 0 to 30 diopters $\left(\mathrm{D} ; 1 \mathrm{D}=.57^{\circ}\right.$ of arc), and afforded binocular vision. Each eyepiece subtended a visual angle of approximately $30^{\circ}$ and the width of the binocular field was approximately $45^{\circ}$.

\section{Design}

Each experiment employed a randomized groups design with four conditions determined by combinations of terminal or concurrent exposure and one other binary variable: presence or absence of exposure targets in Experiment 1, limited or free head movement during exposure in Experiment 2, and left or right exposed hand in Experiment 3. Before and after exposure in all experiments, the subjects were tested for their ability to localize a visual target straight ahead of the nose (visual shift [VS] test), to point straight ahead of the nose with the exposed hand (proprioceptive shift [PS] test) and with the unexposed hand (proprioceptive shift with nonexposed hand [PN] test), and to point to a straight-ahead visual target with the previously exposed hand (total shift [TS] test) and with the previously unexposed hand (total shift with nonexposed hand [TN] test). In addition, Experiments 2 and 3 involved a sixth localization test, requiring subjects to align their heads to feel straight on their shoulders (head shift [HS] test). Order of these localization tests was 
randomized except for the HS test in Experiment 2, which was taken only after the other five tests had been completed.

\section{Procedure}

The procedure was the same as that employed by Wallace and Redding (1979). Specifically, each subject individually was led, blindfolded, to the experimental room and seated in a chair before the apparatus. The blindfold consisted of the goggles with the Risley prisms set to $0 \mathrm{D}$ and with a thick flap over each eyepiece occluding the subject's vision. The subject's head was then positioned in the head- and chinrest and the experimenter asked the subject to perform each of the preexposure localization tests.

The PS and PN tests required the subject to place his/her right or left hand on the lower layer of the apparatus and to point (sagittally) to the position in space believed to be straight ahead of the nose. This task was accomplished with vision occluded. Straightahead localization was performed 10 times with each hand.

The TS and TN tests were similar, except that the subject was not blindfolded but pointed to a visible, vertical target $(.2 \times 8 \mathrm{~cm})$ located in the physically straight-ahead position. During this test, the subject viewed the target with no visual displacement (i.e., 0-D prism setting), but pointing accuracy was not known to the subject since the hand was on the lower level of the apparatus and was not visible. Ten measures were taken for each hand.

The VS test required no arm movement. Instead, the experimenter introduced a moving, visible, vertical target $(.2 \times 8 \mathrm{~cm})$ on the upper layer of the apparatus. When the experimenter moved this target laterally across the subject's visual field, the subject simply indicated when the target appeared to be straight ahead of his/her nose. A total of 10 trials were given. Five trials started with the target randomly positioned in the right half of the visual field, and five trials started with the target randomly positioned in the left visual field. Order of left/right starting positions was random. The prisms were set at $0 \mathrm{D}$ for the VS test, as was true for all test situations in these experiments.

For the HS test, the subject's vision was occluded, the chinrest was loosened, the subject's head was turned to a random starting position (equally frequently left and right), and the subject was instructed to turn the head about a vertical axis until it was straight on the shoulders. Thus, this measure was taken under the same conditions as the other measures and was designed to be sensitive to head shifts that might influence performance on the other tests. Head position was measured on a scale mounted on the base of the chinrest. Ten pretest measures were obtained.

Following establishment of the pretest baselines, the prisms were set to $20 \mathrm{D}$ base left (rightward displacement) and the subject was randomly assigned to one of four exposure conditions, depending upon the experiment. For target-present conditions, the subjects pointed (sagittally), in a random order, 20 times to each of three simultaneously visible targets $(.2 \times 8 \mathrm{~cm}$ vertical black lines at a distance of $60 \mathrm{~cm}$ ) that were optically straight ahead, $5^{\circ}$ left of straight ahead, and $5^{\circ}$ right of straight ahead. The targets were physically positioned to compensate for the binocular base-left 20-D displacement in such a way that they appeared optically and phenomenally symmetrical in the lighted but otherwise white homogeneous visual field. For target-absent conditions, subjects simply pointed to the center of the field a total of 60 times.

For terminal exposure conditions, a horizontal white shelf just below eye level occluded any view of the pointing hand except for the tip (to the first joint) of the index finger when it appeared at the back of the adjustable shelf. In this condition, the subject usually configured his/her hand with palm up and curved the tip of the index finger up over the edge of the occluding shelf (cf. Cohen, 1967). For concurrent exposure conditions, the shelf was removed and the entire hand was visible for most of the normally visible trajectory of a sagittal pointing movement. In neither exposure condition were subjects able to actually touch the target. The average duration of exposure was about $3 \mathrm{~min}$ in all conditions.

Immediately after the exposure period the prisms were reset to $0 \mathrm{D}$, the subject was told that the distortion had been removed, and the localization tests were repeated. Level of adaptation (in degrees of arc) was calculated by taking the signed difference between the average of 10 pretests and 10 posttests, the adaptive (positive) direction of change being in the direction of the displacement for the VS and HS tests and opposite the displacement for the other tests (Harris, 1974; Welch, 1974). All measurements were to the nearest whole degree. Throughout the experiments, except when head movement was manipulated or head position was measured, the subject's head was constrained by the combination head- and chinrest and the head was monitored to correct any changes in head position. All pointing movements, in both exposure and test, were paced by a metronome set at the rate of one beat per $1.5 \mathrm{sec}$. The subject was instructed to complete one out-and-back movement of the hand every $3 \mathrm{sec}$.

\section{EXPERIMENT 1: EXPOSURE TARGETS}

The first experiment was designed to replicate the conditions of terminal and concurrent exposure (e.g. Uhlarik \& Canon, 1971) and to test for any facilitating effects of targets for pointing responses during exposure. The presence of targets for eye-hand coordination responses is generally believed to enhance prism adaptation (for a review see Welch, 1978, pp. 29-31). Unfortunately, most of the studies reporting this effect have not included component tests and we have no idea about, for example, differential effects of targets on visual and proprioceptive adaptation. The most obvious explanation of the "target pointing effect" is that the presence of targets enables more precise determination of error, increasing the precision of the detected discordance between visual and proprioceptive positions, and thereby enhances the speed of the adaptive process. According to this precision hypothesis, the target manipulation has no effect on the kind of adaptation, but adaptation of any kind should be greater with than without exposure targets.

One possible explanation of the differential effects of terminal and concurrent exposure is that the locus of adaptation resides in the bodily articulation whose behavior is forced to change during exposure (e.g., Hamilton, 1964; Howard \& Templeton, 1966, p. 380). Thus, terminal exposure may produce more visual adaptation because the eyes are forced to make a rather large jump from expected to observed finger position, and concurrent exposure may produce more proprioceptive adaptation because the seen hand is forced to make corrective movements "in flight." According to this corrective-exercise hypothesis, the presence of a specific target should enable more precise exercise of whatever behavior is supported by the exposure condition, and the effect of terminal versus concurrent exposure on the relative magnitude of VS and PS should be larger with than without targets.

\section{Method}

Twelve subjects were randomly assigned to each of the four conditions determined by combinations of exposure targets present or 
Table 1

Level of Adaptation (in Degrees) and 95\% Confidence Limits for the Visual Shift Test and for the Proprioceptive Shift and Total Shift Tests With the Exposed Hand as a Function of Combinations of Exposure Targets Present or Absent and Terminal or Concurrent Exposure (Experiment 1)

\begin{tabular}{|c|c|c|c|c|c|c|c|}
\hline \multirow[b]{3}{*}{ Test } & \multirow[b]{3}{*}{ Exposure } & \multicolumn{4}{|c|}{ Target } & & \\
\hline & & \multicolumn{2}{|c|}{ Present } & \multicolumn{2}{|c|}{ Absent } & \multicolumn{2}{|c|}{$\boldsymbol{M}$} \\
\hline & & LA & $\mathrm{CL}$ & LA & CL & LA & $\mathrm{CL}$ \\
\hline VS & $\begin{array}{l}\mathrm{T} \\
\mathrm{C} \\
M\end{array}$ & $\begin{array}{l}2.1 \\
0.8 \\
1.4\end{array}$ & $\begin{array}{l}1.5 \\
0.7 \\
0.8\end{array}$ & $\begin{array}{l}2.7 \\
0.4 \\
1.5\end{array}$ & $\begin{array}{l}1.4 \\
0.3 \\
0.8\end{array}$ & $\begin{array}{l}2.4 \\
0.6 \\
1.5\end{array}$ & $\begin{array}{l}1.0 \\
0.4 \\
0.6\end{array}$ \\
\hline PS & $\begin{array}{l}\mathrm{T} \\
\mathrm{C} \\
M\end{array}$ & $\begin{array}{l}1.1 \\
3.2 \\
2.2\end{array}$ & $\begin{array}{l}0.8 \\
1.1 \\
0.8\end{array}$ & $\begin{array}{l}1.3 \\
2.3 \\
1.8\end{array}$ & $\begin{array}{l}0.7 \\
0.6 \\
0.5\end{array}$ & $\begin{array}{l}1.2 \\
2.7 \\
2.0\end{array}$ & $\begin{array}{l}0.5 \\
0.6 \\
0.4\end{array}$ \\
\hline TS & $\begin{array}{l}\mathrm{T} \\
\mathrm{C} \\
M\end{array}$ & $\begin{array}{l}3.9 \\
5.0 \\
4.5\end{array}$ & $\begin{array}{l}0.8 \\
1.5 \\
0.8\end{array}$ & $\begin{array}{l}2.8 \\
2.8 \\
2.8\end{array}$ & $\begin{array}{l}0.9 \\
0.8 \\
0.6\end{array}$ & $\begin{array}{l}3.4 \\
3.9 \\
3.6\end{array}$ & $\begin{array}{l}0.6 \\
0.9 \\
0.5\end{array}$ \\
\hline $\mathrm{VS}+\mathrm{PS}$ & $\begin{array}{l}\mathrm{T} \\
\mathrm{C} \\
M\end{array}$ & $\begin{array}{l}3.2 \\
3.9 \\
3.6\end{array}$ & $\begin{array}{l}1.9 \\
1.6 \\
1.1\end{array}$ & $\begin{array}{l}4.0 \\
2.7 \\
3.4\end{array}$ & $\begin{array}{l}1.2 \\
0.8 \\
0.7\end{array}$ & $\begin{array}{l}3.6 \\
3.3 \\
3.5\end{array}$ & $\begin{array}{l}1.1 \\
0.8 \\
0.6\end{array}$ \\
\hline
\end{tabular}

Note-LA $=$ level of adaptation, $\mathrm{CL}=$ confidence limits, $\mathrm{VS}=$ visual shift, $\mathrm{PS}=$ proprioceptive shift, $\mathrm{TS}=$ total shift, $\mathrm{T}=$ terminal, $\mathrm{C}=$ concurrent.

absent and terminal or concurrent exposure. Before and after exposure all 48 subjects received the VS, PS, PN, TS, and TN tests in a random order.

\section{Results and Discussion}

Locus and additivity of adaptation (VS, PS, and TS measures). The data for comparisons involving VS, PS, and TS measures for the exposed (right) hand are displayed in Table 1. Analysis of variance performed on the VS and PS data revealed that the exposure $x$ test interaction was the only significant source of variance $[F(1,44)$ $=28.83, p<.001]$. Thus, VS was greater than PS with terminal exposure $[F(1,23)=4.05, p<.05]$, but the relative magnitude of the two components was reversed for concurrent exposure $[F(1,23)=62.85, p<.001]$.

The results for terminal and concurrent exposures were a very close replication of those of Uhlarik and Canon (1971). The effect of these exposure conditions, therefore, seems to be reliable. Moreover, it does not depend upon the presence of exposure targets, it occurs whether adaptation is measured directly with prisms in place (as in Uhlarik \& Canon, 1971) or as aftereffects without the prisms (as in the present study), and it occurs whether visual exposure targets are optically asymmetrical (as in Uhlarik \& Canon, 1971) or symmetrical (as in the present study). These conclusions seem to rule out forced exercise, conscious correction, or eye-muscle potentiation as factors contributing to the differential relative magnitude of VS and PS with terminal and concurrent exposures. Indeed, informal observation suggests that pointing error during exposure disappears for the majority of subjects within two trials and for all subjects after about for trials. Thus, there is little occasion for jumps of the eye or for asymmetric eye posture arising from fixation of the hand when an error was made. ${ }^{3}$
The target manipulation was almost completely without consequence in these data. Only the main effect of the target manipulation was significant for the TS measure $[F(1,44)=32.51, p<.005]$, indicating that TS aftereffects are larger when targets are present during exposure. Comparison of TS with the sum VS + PS revealed a significant target $\times$ measure interaction $[F(1,44)=$ $7.35, p<.01]$, but the only significant deviation from additivity (i.e, VS +PS $=$ TS) occurred when targets were present $[F(1,23)=4.73, p<.05]$. The sum VS+PS (3.6) is about $1.0^{\circ}$ less than TS (4.5).

The absence of significant effects involving the target manipulation for either the VS or PS measures provides no support for the idea that the presence of a target increases the precision of error detection and thereby speeds the acquisition of VS or PS. The presence of exposure targets produced a greater change only when the test required the subject to point to visible targets (i.e., for TS). This target-pointing effect replicates the effects found in previous studies (e.g., Wallace, 1974) and suggests that the presence of an exposure target encourages assimilation of an error-corrective motor response (Welch, 1974; Welch et al., 1974) that is not available for either the VS or the PS test. This conclusion is supported by the fact that the only significant deviation from additivity (i.e., VS +PS = TS; e.g., Wilkinson, 1971) in these data occurred when the targets were present. The $1.0^{\circ}$ of underadditivity (Redding \& Wallace, 1978) may be assumed to represent the magnitude of the assimilated corrective response (Welch et al., 1974). Thus, the only effect of target availability appears to be a small motor-learning contamination of the TS measure.

Intermanual transfer (PS and PN measures). The data for evaluating intermanual transfer of PS are displayed in Table 2. Overall, the aftereffect measured for the unexposed (left) hand (.4) was only about $20 \%$ of that for the exposed hand $(2.0)[F(1,44)=69.35, p<.001]$, and these two measures were affected by different factors. For both measures there was a slight tendency for aftereffects to be larger for exposure conditions in which targets were present, but none of the sources of variance

Table 2

Level of Adaptation (in Degrees) and 95\% Confidence Limits for Pointing Without Vision With Exposed Hand and Unexposed Hand as a Function of Combinations of Exposure Targets Present or Absent and Terminal or Concurrent Exposure (Experiment 1)

\begin{tabular}{|c|c|c|c|c|c|c|c|}
\hline \multirow[b]{3}{*}{ Test } & \multirow[b]{3}{*}{ Exposure } & \multicolumn{4}{|c|}{ Target } & \multirow{2}{*}{\multicolumn{2}{|c|}{$M$}} \\
\hline & & \multicolumn{2}{|c|}{ Present } & \multicolumn{2}{|c|}{ Absent } & & \\
\hline & & LA & $\overline{\mathrm{CL}}$ & LA & $\overline{C L}$ & $\overline{\mathbf{L A}}$ & CL \\
\hline Exposed Hand (PS) & $\begin{array}{l}\mathrm{T} \\
\mathrm{C} \\
M\end{array}$ & $\begin{array}{l}1.1 \\
3.2 \\
2.2\end{array}$ & $\begin{array}{l}0.8 \\
1.1 \\
0.8\end{array}$ & $\begin{array}{l}1.3 \\
2.3 \\
1.8\end{array}$ & $\begin{array}{l}0.7 \\
0.6 \\
0.5\end{array}$ & $\begin{array}{l}1.2 \\
2.7 \\
2.0\end{array}$ & $\begin{array}{l}0.5 \\
0.6 \\
0.4\end{array}$ \\
\hline Unexposed Hand (PN) & $\begin{array}{l}\mathrm{T} \\
\mathrm{C} \\
M\end{array}$ & $\begin{array}{l}0.7 \\
0.6 \\
0.7\end{array}$ & $\begin{array}{l}0.5 \\
0.3 \\
0.3\end{array}$ & $\begin{array}{l}0.1 \\
0.3 \\
0.2\end{array}$ & $\begin{array}{l}0.4 \\
0.4 \\
0.3\end{array}$ & $\begin{array}{l}0.4 \\
0.4 \\
0.4\end{array}$ & $\begin{array}{l}0.3 \\
0.2 \\
0.2\end{array}$ \\
\hline
\end{tabular}

Note-LA = level of adaptation, $\mathrm{CL}=$ confidence limits, $\mathrm{PS}=$ proprioceptive shift, $\mathrm{PN}=$ proprioceptive shift with nonexposed hand, $\mathrm{T}=$ terminal, $\mathbf{C}=$ concurrent. 
involving this factor were significant $(p>.05)$. More importantly, concurrent exposure produced larger aftereffects on the exposed hand, but there was no effect of exposure conditions on the unexposed hand $[F(1,44)=$ $14.73, p<.001]$. Thus, these data suggest that the component of proprioceptive adaptation affected by concurrent exposure does not transfer to the unexposed hand.

The present data do not support the idea that there is much, or any, direct intermanual transfer of change in felt arm position, and the obtained transfer is subject to alternative interpretation (Welch, 1978, p. 95). Specifically, the small but reliable aftereffects measured with the unexposed hand might be due to a change in felt head position. The PS test used here was referenced to the head and is logically sensitive to any changes in proprioception from head to hand. Thus, the $20 \%$ intermanual transfer may reflect a feeling that the straight head is turned opposite the displacement direction after exposure, which would contribute to measures obtained with either the exposed or unexposed hand. Although there is little direct evidence of such a change in felt head position with prism exposure (Welch, 1978, pp. 63-64), the present results suggest that its magnitude is small and that it might be difficult to detect among the larger effects on other components of PS produced by exposure conditions.

Target pointing transfer (TS, TN, and VS measures). Table 3 displays the data evaluating intermanual transfer of target pointing aftereffects and comparison with VS. Overall, the aftereffect measured for the unexposed hand (.9) is only about $25 \%$ of that measured for the exposed hand $(3.6)[F(1,44)=153.86, p<.001]$ and about $60 \%$ of the visual aftereffect $(1.5)[F(1,44)=5.83, p<.05]$. Most importantly, the VS and TN measures were affected by different factors. Terminal exposure produced more VS, but there was no effect of exposure conditions for the TN measure $[F(1,44)=12.43, p<.025]$. Thus, these data suggest that the component of visual adapta-

Table 3

Level of Adaptation (in Degrees) and 95\% Confidence Limits for the Visual Shift Test and for Target Pointing With the Unexposed Hand and Exposed Hand as a Function of Combinations of Exposure Targets Present or Absent and Terminal or Concurrent Exposure (Experiment 1)

\begin{tabular}{|c|c|c|c|c|c|c|c|}
\hline \multirow[b]{3}{*}{ Test } & \multirow[b]{3}{*}{ Exposure } & \multicolumn{4}{|c|}{ Target } & \multirow{2}{*}{\multicolumn{2}{|c|}{$M$}} \\
\hline & & \multicolumn{2}{|c|}{ Present } & \multicolumn{2}{|c|}{ Absent } & & \\
\hline & & $\overline{\mathrm{LA}}$ & $\overline{\mathrm{CL}}$ & LA & $\mathrm{CL}$ & LA & CL \\
\hline VS & $\begin{array}{l}\mathrm{T} \\
\mathrm{C} \\
M\end{array}$ & $\begin{array}{l}2.1 \\
0.8 \\
1.4\end{array}$ & $\begin{array}{l}1.5 \\
0.7 \\
0.8\end{array}$ & $\begin{array}{l}2.7 \\
0.4 \\
1.5\end{array}$ & $\begin{array}{l}1.4 \\
0.3 \\
0.8\end{array}$ & $\begin{array}{l}2.4 \\
0.6 \\
1.5\end{array}$ & $\begin{array}{l}1.0 \\
0.4 \\
0.6\end{array}$ \\
\hline Unexposed Hand (TN) & $\begin{array}{l}\mathrm{T} \\
\mathrm{C} \\
M\end{array}$ & $\begin{array}{l}0.9 \\
1.2 \\
1.0\end{array}$ & $\begin{array}{l}0.2 \\
0.4 \\
0.2\end{array}$ & $\begin{array}{l}0.9 \\
0.6 \\
0.7\end{array}$ & $\begin{array}{l}0.3 \\
0.2 \\
0.2\end{array}$ & $\begin{array}{l}0.9 \\
0.9 \\
0.9\end{array}$ & $\begin{array}{l}0.2 \\
0.3 \\
0.2\end{array}$ \\
\hline Exposed Hand (TS) & $\begin{array}{l}\mathrm{T} \\
\mathrm{C} \\
M\end{array}$ & $\begin{array}{l}3.9 \\
5.0 \\
4.5\end{array}$ & $\begin{array}{l}0.8 \\
1.5 \\
0.8\end{array}$ & $\begin{array}{l}2.8 \\
2.8 \\
2.8\end{array}$ & $\begin{array}{l}0.9 \\
0.8 \\
0.6\end{array}$ & $\begin{array}{l}3.4 \\
3.9 \\
3.6\end{array}$ & $\begin{array}{l}0.6 \\
0.9 \\
0.5\end{array}$ \\
\hline
\end{tabular}

Note--LA $=$ level of adaptation, $\mathrm{CL}=$ confidence limits, $\mathrm{VS}=$ visual shift, $\mathrm{TN}=$ total shift with nonexposed hand, $\mathrm{TS}=$ total shift, $\mathrm{T}=$ terminal, $\mathbf{C}=$ concurrent. tion affected by terminal exposure does not transfer to target pointing with the unexposed hand.

The meaning of these TN data is problematical. Within the constraints of the additivity model and the assumptions underlying the present tests, there appears to be no logical way TN could be less than VS. In any case, it is clear that target pointing with the unexposed hand is not a simple measure of adaptation in the visual system, and previous researchers (e.g., Cohen, 1967; Freedman, 1968) are not justified in making this assumption.

\section{EXPERIMENT 2}

Experiment 1 established the reliability of the effect of terminal versus concurrent exposure on the relative magnitude of VS and PS, and further determined that this result does not depend upon the presence of exposure targets and is unlikely to involve effects of asymmetric eye posture. Experiment 2 was designed to investigate head movement during exposure. In contrast to our findings in Experiment 1, in which the head was largely immobilized, Wallace and Redding (1979) found that VS was less than PS with terminal exposure when the head was permitted some movement during exposure by loosening the chinrest. This condition has also been shown to maximize the magnitude of intermanual transfer (Wallace, 1978). Thus, Experiment 2 replicated the conditions of Experiment 1 , but without targets and with two head-movement conditions (fixed and unconstrained). In addition, an attempt was made to measure directly change in felt head position.

\section{Method}

The method was similar to that used in Experiment 1, except that exposure targets were absent in all conditions and for half of the subjects the chinrest was loosened so that the head was permitted some movement during exposure. Thus, there were four groups of 12 subjects each, determined by the factorial combination of exposure condition (terminal or concurrent) and head-movement condition (fixed or unconstrained). The only other difference from the first experiment was that after all five of the tests had been administered (before and after exposure), head shift (HS) was measured by loosening the chinrest and having the subject turn his/her head to straight on the shoulders (see General Method).

\section{Results and Discussion}

Locus and additivity. The data for comparisons involving VS, PS, and TS measured for the exposed (right) hand are displayed in Table 4. As in Experiment 1, analysis of the VS and PS data revealed that the exposure $x$ test interaction was the only significant source of variance in these data $[F(1,44)=17.99, p<.001]$. Again, VS was greater than PS with terminal exposure, but the reverse was true for concurrent exposure. However, when the head was free to move during exposure there was a lowreliability tendency for VS to be less than PS even with terminal exposure $[F(1,44)=3.76, p=.06]$. Thus, these data confirm the suggestion of Wallace and Redding (1979) that the effects of terminal exposure are different 
Table 4

Level of Adaptation (in Degrees) and 95\% Confidence Limits for the Visual Shift Test and for Proprioceptive Shift and Total Shif

Tests With the Exposed Hand as a Function of Combinations of Head Unconstrained or Fixed During Terminal or Concurrent Exposure (Experiment 2)

\begin{tabular}{|c|c|c|c|c|c|c|c|}
\hline \multirow[b]{3}{*}{ Test } & \multirow[b]{3}{*}{ Exposure } & \multicolumn{4}{|c|}{ Head } & \multirow{2}{*}{\multicolumn{2}{|c|}{$M$}} \\
\hline & & \multicolumn{2}{|c|}{ Unconstrained } & \multicolumn{2}{|c|}{ Fixed } & & \\
\hline & & LA & $\mathrm{CL}$ & LA & $\mathrm{CL}$ & LA & $\mathrm{CL}$ \\
\hline VS & $\begin{array}{l}\mathrm{T} \\
\mathrm{C} \\
M\end{array}$ & $\begin{array}{l}1.3 \\
0.7 \\
1.0\end{array}$ & $\begin{array}{l}0.7 \\
0.4 \\
0.4\end{array}$ & $\begin{array}{l}2.5 \\
0.7 \\
1.6\end{array}$ & $\begin{array}{l}0.9 \\
0.5 \\
0.6\end{array}$ & $\begin{array}{l}1.9 \\
0.7 \\
1.3\end{array}$ & $\begin{array}{l}0.6 \\
0.3 \\
0.4\end{array}$ \\
\hline PS & $\begin{array}{l}\mathrm{T} \\
\mathrm{C} \\
M\end{array}$ & $\begin{array}{l}1.7 \\
2.3 \\
2.0\end{array}$ & $\begin{array}{l}1.1 \\
1.1 \\
0.7\end{array}$ & $\begin{array}{l}0.8 \\
2.4 \\
1.6\end{array}$ & $\begin{array}{l}0.8 \\
1.4 \\
0.8\end{array}$ & $\begin{array}{l}1.2 \\
2.4 \\
1.8\end{array}$ & $\begin{array}{l}0.6 \\
0.8 \\
0.5\end{array}$ \\
\hline TS & $\begin{array}{l}\mathrm{T} \\
\mathrm{C} \\
M\end{array}$ & $\begin{array}{l}3.4 \\
3.5 \\
3.4\end{array}$ & $\begin{array}{l}1.1 \\
1.0 \\
0.7\end{array}$ & $\begin{array}{l}3.9 \\
3.3 \\
3.6\end{array}$ & $\begin{array}{l}1.5 \\
1.0 \\
0.8\end{array}$ & $\begin{array}{l}3.6 \\
3.4 \\
3.5\end{array}$ & $\begin{array}{l}0.8 \\
0.6 \\
0.5\end{array}$ \\
\hline $\mathrm{VS}+\mathrm{PS}$ & $\begin{array}{l}\mathrm{T} \\
\mathrm{C} \\
\mathrm{M}\end{array}$ & $\begin{array}{l}3.0 \\
3.0 \\
3.0\end{array}$ & $\begin{array}{l}1.4 \\
1.2 \\
0.8\end{array}$ & $\begin{array}{l}3.3 \\
3.0 \\
3.2\end{array}$ & $\begin{array}{l}1.4 \\
1.5 \\
1.0\end{array}$ & $\begin{array}{l}3.2 \\
3.0 \\
3.1\end{array}$ & $\begin{array}{l}0.9 \\
0.9 \\
0.6\end{array}$ \\
\hline
\end{tabular}

Note $-\mathrm{LA}=$ level of adaptation, $\mathrm{CL}=$ confidence limits, $\mathrm{VS}=$ visual shift, $\mathrm{PS}=$ proprioceptive shift, $\mathrm{TS}=$ total shift, $\mathrm{T}=$ terminal, $\mathrm{C}=$ concurrent.

when the head is fixed and when it is permitted some movement during exposure. Nevertheless, these data show almost perfect additivity. The sum VS + PS (3.1) is not significantly different from TS $(3.5)[F(1,44)=.93]$, and all other sources of variance in this analysis have associated $F$ ratios less than 1.00 .

The presence of additivity argues against the possibility that the effects of terminal exposure with head movement on the relative magnitude of VS and PS might be due to contamination of the presumed head-relative VS test by a change in felt head position. Since it is very reasonable to assume that the PS test is sensitive to any change in felt head position, if the VS test were also sensitive, the result should have been overadditivity (Red- ding \& Wallace, 1978). It is therefore likely that when the head is permitted movement it assumes an unperceived asymmetric posture that reduces discordance (and therefore the stimulus for perceptual recalibration) while producing postural aftereffects (Ebenholtz, 1976; Howard \& Anstis, 1974) that appear as part of PS.

Intermanual transfer. Only main effects proved to be significant in analysis of variance of the PS and PN data shown in Table 5. Pointing aftereffects were larger when the head was unconstrained (1.7) than when it was fixed (1.0) $[F(1,44)=7.97, p<.025]$, larger for concurrent exposure (1.6) than for terminal exposure $(1.1)[F(1,44)$ $=4.45, p<.05$ ], and larger for the exposed hand (1.8) than for the unexposed hand $(0.9)[F(1,44)=8.93, p<$ $.025]$. Although the relevant interaction did not prove to be very reliable $[F(1,44)=3.70, p=.06]$, the data are consistent with those of Wallace (1978) in showing the largest intermanual transfer ( $82 \%$ ) when some head movement was permitted during terminal exposure, and with Experiment 1 in showing the smallest intermanual transfer $(17 \%)$ when the head was fixed during concurrent exposure. Again, the data suggest that the component of proprioceptive adaptation affected by concurrent exposure does not transfer to the unexposed hand.

Intermanual transfer seems to be a measure of change in felt head position rather than felt arm position. If the straight head is felt to be turned opposite the displacement direction after exposure, then the subject would point in this direction on the PN test even if there were no direct internanual transfer of proprioceptive adaptation in the exposed arm. Consistent with this idea is the finding that the unexposed hand aftereffect and the HS measure differ only in relative magnitude $[F(1,44)=26.05, p<.001]$ and are both similarly affected by the head-movement manipulation $[F(1,44)=24.04, p<.001]$. Since the HS measures were all taken after the other tests, this measure may have suffered some decay; HS may be underes-

Table 5

Level of Adaptation (in Degrees) and 95\% Confidence Limits for Pointing Without Vision With the Exposed Hand and the Unexposed

Hand and for the Head Shift Test as a Function of Combinations of Head Unconstrained or Fixed During Terminal or Concurrent Exposure (Experiment 2)

\begin{tabular}{|c|c|c|c|c|c|c|c|}
\hline \multirow[b]{3}{*}{ Test } & \multirow[b]{3}{*}{ Exposure } & \multicolumn{4}{|c|}{ Head } & \multirow{2}{*}{\multicolumn{2}{|c|}{$M$}} \\
\hline & & \multicolumn{2}{|c|}{ Unconstrained } & \multicolumn{2}{|c|}{ Fixed } & & \\
\hline & & $\overline{\text { LA }}$ & $\mathrm{CL}$ & LA & $\mathrm{CL}$ & LA & $\mathrm{CL}$ \\
\hline Exposed Hand (PS) & $\begin{array}{l}\mathrm{T} \\
\mathrm{C} \\
M\end{array}$ & $\begin{array}{l}1.7 \\
2.3 \\
2.0\end{array}$ & $\begin{array}{l}1.1 \\
1.1 \\
0.7\end{array}$ & $\begin{array}{l}0.8 \\
2.4 \\
1.6\end{array}$ & $\begin{array}{l}0.8 \\
1.4 \\
0.8\end{array}$ & $\begin{array}{l}1.2 \\
2.4 \\
1.8\end{array}$ & $\begin{array}{l}0.6 \\
0.8 \\
0.5\end{array}$ \\
\hline Unexposed Hand (PN) & $\begin{array}{l}\mathrm{T} \\
\mathrm{C} \\
M\end{array}$ & $\begin{array}{l}1.4 \\
1.3 \\
1.4\end{array}$ & $\begin{array}{l}0.6 \\
0.6 \\
0.4\end{array}$ & $\begin{array}{l}0.4 \\
0.4 \\
0.4\end{array}$ & $\begin{array}{l}0.4 \\
0.4 \\
0.2\end{array}$ & $\begin{array}{l}0.9 \\
0.9 \\
0.9\end{array}$ & $\begin{array}{l}0.3 \\
0.3 \\
0.3\end{array}$ \\
\hline HS & $\begin{array}{l}\mathrm{T} \\
\mathrm{C} \\
\mathrm{M}\end{array}$ & $\begin{array}{l}0.4 \\
0.4 \\
0.4\end{array}$ & $\begin{array}{l}0.2 \\
0.4 \\
0.2\end{array}$ & $\begin{array}{l}-0.2 \\
-0.1 \\
-0.2\end{array}$ & $\begin{array}{l}0.4 \\
0.6 \\
0.3\end{array}$ & $\begin{array}{l}0.1 \\
0.2 \\
0.1\end{array}$ & $\begin{array}{l}0.2 \\
0.4 \\
0.2\end{array}$ \\
\hline
\end{tabular}

Note-LA = level of adaptation, $\mathrm{CL}=$ confidence limits, $\mathrm{PS}=$ proprioceptive shift, PN = proprioceptive shift with nonexposed hand, HS = head shift, T = terminal, $\mathrm{C}=$ concurrent . 
timated in these data and it is possible to entertain the idea that all intermanual transfer has its basis in a change in felt head position.

The fact that small but reliable HS occurred only when the head was free to move during exposure $[F(1,44)=$ $7.72, p<.01]$ suggests an asymmetric posture (e.g., Ebenholtz, 1976; Howard \& Anstis, 1974) rather than a perceptual recalibration basis for the aftereffect. Turning the head in the displacement direction would tend to center the straight-ahead but optically displaced hand in the visual field and thereby facilitate the pointing task, especially in terminal exposure, when the finger is visible only at the end of the movement. As a consequence of such an asymmetric head posture, the relaxed neck would tend to turn the head in the displacement direction and the straight head would tend to feel turned opposite the displacement, with the aftereffect being in the displacement direction. If the basis of HS were more central perceptual recalibration, HS should have appeared even when the head was constrained, since discordance between seen and felt head position is certainly present.

Target pointing transfer. As can be seen in Table 6, target pointing transfer was larger in Experiment 2 than in Experiment 1. Overall, the aftereffect measured for the unexposed hand $(1.5)$ was about $40 \%$ of that measured for the exposed hand $(3.5)[F(1,44)=39.86, p<.001]$ and $100 \%$ of the visual aftereffect $(1.3)[F(1,44)=.76]$. Again, however, the VS and TN measures were affected by different variables. Terminal exposure produced more VS, but there was no effect of exposure conditions for the TN measure $[F(1,44)=7.02, p<.05]$. Consistent with Experiment 1, the component of visual adaptation affected by terminal exposure did not seem to transfer to target pointing with the unexposed hand. The TN measure was greatest when the head was permitted some movement, but VS was little affected by this manipulation $[F(1,44)=25.60, p<.001]$.

Even more than those of Experiment 1, the present results suggest caution in interpreting target pointing transfer as a measure of visual adaptation. Under different exposure conditions, the transfer measure varied from greater than to less than the VS measure. Clearly, the TN measure is unrelated to the VS measure, and it seems unlikely to be a measure of visual adaptation. The similarity in pattern among the TN, PN, and HS measures suggests that the TN measure is most sensitive to changes in felt head position.

\section{EXPERIMENT 3}

In Experiment 3 we tested the generalizability of the terminal versus concurrent exposure effects for the exposed left hand as well as for the right hand. Thus, this experiment provided a control for any unknown bias effects arising from the particular hand exposed. In addition, the design was corrected to remove the possibility of greater decay due to delay in obtaining the HS measure.

\section{Method}

The fixed-head, no-target conditions of the previous experiment were replicated for the exposed left hand as well as for the right hand. Fifteen subjects were randomly assigned to each of the four conditions determined by factorial combinations of terminal or concurrent exposure and whether the left or right hand was used during exposure. The HS test was randomly mixed with the other five pre- and posttests. In all other respects the method was identical to that used in Experiments 1 and 2.

\section{Results and Discussion}

Locus and additivity. The data for comparisons involving VS, PS, and TS measures for the exposed hand are displayed in Table 7. As in the preceding experiments, analysis of variance performed on the VS and PS data revealed that the exposure $X$ test interaction was the only significant source of variance $[F(1,56)=30.29, p<$ $.001]$. Thus, VS was greater than PS with terminal exposure $[F(1,29)=8.64, p<.01]$, and PS was greater than VS with concurrent exposure $[F(1,29)=23.29, p<$ .001 ]. Comparison of TS (3.7) with the sum VS+PS (3.8)

Table 6

Level of Adaptation (in Degrees) and 95\% Confidence Limits for the Visual Shift

Test and for Target Pointing With the Unexposed Hand and Exposed Hand as a Function of Combinations of Head Unconstrained or Fixed During Terminal or Concurrent Exposure (Experiment 2)

\begin{tabular}{|c|c|c|c|c|c|c|c|}
\hline \multirow[b]{3}{*}{ Test } & \multirow[b]{3}{*}{ Exposure } & \multicolumn{4}{|c|}{ Head } & \multirow{2}{*}{\multicolumn{2}{|c|}{$M$}} \\
\hline & & \multicolumn{2}{|c|}{ Unconstrained } & \multicolumn{2}{|c|}{ Fixed } & & \\
\hline & & LA & $\mathbf{C L}$ & LA & $\mathrm{CL}$ & LA & CL \\
\hline VS & $\begin{array}{l}\mathrm{T} \\
\mathrm{C} \\
M\end{array}$ & $\begin{array}{l}1.3 \\
0.7 \\
1.0\end{array}$ & $\begin{array}{l}0.7 \\
0.7 \\
0.4\end{array}$ & $\begin{array}{l}2.5 \\
0.7 \\
1.6\end{array}$ & $\begin{array}{l}0.9 \\
0.3 \\
0.6\end{array}$ & $\begin{array}{l}1.9 \\
0.7 \\
1.3\end{array}$ & $\begin{array}{l}0.6 \\
0.4 \\
0.4\end{array}$ \\
\hline Unexposed Hand (TN) & $\begin{array}{l}\mathrm{T} \\
\mathrm{C} \\
M\end{array}$ & $\begin{array}{l}2.3 \\
2.4 \\
2.3\end{array}$ & $\begin{array}{l}0.9 \\
0.4 \\
0.7\end{array}$ & $\begin{array}{l}0.8 \\
0.5 \\
0.6\end{array}$ & $\begin{array}{l}0.5 \\
0.2 \\
0.3\end{array}$ & $\begin{array}{l}1.5 \\
1.5 \\
1.5\end{array}$ & $\begin{array}{l}0.6 \\
0.3 \\
0.4\end{array}$ \\
\hline Exposed Hand (TS) & $\begin{array}{l}\mathrm{T} \\
\mathrm{C} \\
M\end{array}$ & $\begin{array}{l}3.4 \\
3.5 \\
3.4\end{array}$ & $\begin{array}{l}1.1 \\
1.0 \\
0.7\end{array}$ & $\begin{array}{l}3.9 \\
3.3 \\
3.6\end{array}$ & $\begin{array}{l}1.5 \\
1.0 \\
0.8\end{array}$ & $\begin{array}{l}3.6 \\
3.4 \\
3.5\end{array}$ & $\begin{array}{l}0.8 \\
0.6 \\
0.5\end{array}$ \\
\hline
\end{tabular}

Note-LA $=$ level of adaptation, $\mathrm{CL}=$ confidence limits, $\mathrm{VS}=$ visual shift, $\mathrm{TN}=$ total shift with nonexposed hand, $\mathrm{TS}=$ total shift, $\mathrm{T}=$ terminal, $\mathrm{C}=$ concurrent. 
Table 7

Level of Adaptation (in Degrees) and 95\% Confidence Limits for the Visual Shift Test and for Proprioceptive Shift and Total Shift

Tests With the Exposed Hand as a Function of Combinations of Left or Right Hand Exposed and Terminal or Concurrent Exposure (Experiment 3)

\begin{tabular}{|c|c|c|c|c|c|c|c|}
\hline \multirow[b]{3}{*}{ Test } & \multirow[b]{3}{*}{ Exposure } & \multicolumn{4}{|c|}{ Hand } & & \\
\hline & & \multicolumn{2}{|c|}{ Left } & \multicolumn{2}{|c|}{ Right } & \multicolumn{2}{|c|}{$M$} \\
\hline & & LA & $\mathrm{CL}$ & LA & $\mathrm{CL}$ & LA & $\mathrm{CL}$ \\
\hline VS & $\begin{array}{l}\mathrm{T} \\
\mathrm{C} \\
M\end{array}$ & $\begin{array}{l}2.4 \\
0.8 \\
1.6\end{array}$ & $\begin{array}{l}0.9 \\
0.4 \\
0.6\end{array}$ & $\begin{array}{l}2.9 \\
0.6 \\
1.8\end{array}$ & $\begin{array}{l}0.9 \\
1.0 \\
0.8\end{array}$ & $\begin{array}{l}2.6 \\
0.7 \\
1.7\end{array}$ & $\begin{array}{l}0.6 \\
0.5 \\
0.5\end{array}$ \\
\hline PS & $\begin{array}{l}\mathrm{T} \\
\mathrm{C} \\
M\end{array}$ & $\begin{array}{l}1.7 \\
2.7 \\
2.2\end{array}$ & $\begin{array}{l}0.9 \\
1.1 \\
0.7\end{array}$ & $\begin{array}{l}1.3 \\
2.8 \\
2.1\end{array}$ & $\begin{array}{l}0.5 \\
1.5 \\
0.8\end{array}$ & $\begin{array}{l}1.5 \\
2.8 \\
2.2\end{array}$ & $\begin{array}{l}0.5 \\
0.8 \\
0.5\end{array}$ \\
\hline TS & $\begin{array}{l}\mathrm{T} \\
\mathrm{C} \\
M\end{array}$ & $\begin{array}{l}4.1 \\
3.5 \\
3.8\end{array}$ & $\begin{array}{l}1.1 \\
1.2 \\
0.8\end{array}$ & $\begin{array}{l}3.9 \\
3.3 \\
3.6\end{array}$ & $\begin{array}{l}1.3 \\
1.5 \\
1.0\end{array}$ & $\begin{array}{l}4.0 \\
3.4 \\
3.7\end{array}$ & $\begin{array}{l}0.8 \\
0.9 \\
0.9\end{array}$ \\
\hline VS + PS & $\begin{array}{l}\mathrm{T} \\
\mathrm{C} \\
M\end{array}$ & $\begin{array}{l}4.2 \\
3.5 \\
3.8\end{array}$ & $\begin{array}{l}1.2 \\
1.1 \\
0.8\end{array}$ & $\begin{array}{l}4.2 \\
3.4 \\
3.8\end{array}$ & $\begin{array}{l}1.1 \\
2.0 \\
1.1\end{array}$ & $\begin{array}{l}4.2 \\
3.4 \\
3.8\end{array}$ & $\begin{array}{l}0.8 \\
1.1 \\
0.7\end{array}$ \\
\hline
\end{tabular}

Note-LA = level of adaptation, $\mathrm{CL}=$ confidence limits, $\mathrm{VS}=$ visual shift, $\mathrm{PS}=$ proprioceptive shift, $\mathrm{TS}=$ total shift, $\mathrm{T}=$ terminal, $\mathrm{C}=$ concurrent.

revealed no significant deviation from additivity $[F(1,56)<1.00]$. The only source of variance with an $F$ ratio greater than 1.00 was associated with a nonsignificant tendency for concurrent exposure to yield less adaptation than terminal exposure $[F(1,56)=2.16, p=$ .14]. Thus, the effects of exposure conditions and additivity were not affected by which hand was used during exposure.

Intermanual transfer. The data for evaluating intermanual transfer of PS are displayed in Table 8. As in Experiment 1 , in which the head was fixed during exposure, the overall aftereffect measured for the unexposed hand (.4) was only about $18 \%$ of that for the exposed hand (2.2) $[F(1,56)=44.70, p<.001]$, and these two measures were affected by different factors. The aftereffect for the exposed hand (PS) was larger with concurrent than with terminal exposure $[F(1,56)=6.36, p<.025]$, but the aftereffect for the unexposed hand was not reliably affected by either exposure condition or exposed hand $(p>.05)$. Clearly, the component of proprioceptive adaptation affected by concurrent exposure did not transfer to the unexposed hand.

Thus, these data, like those from the previous experiments, suggest little direct intermanual transfer of change in felt arm position; however, the aftereffect for the unexposed hand may be due to change in felt head position. Comparison of the HS measure and the aftereffect in the unexposed hand revealed no reliable effects $(p>.05)$, although there was a nonsignificant tendency for the transfer measure to be larger for the exposed right hand and HS to be larger when the left hand was exposed $[F(1,56)$ $=3.64, p=.06$ ].

Target pointing transfer. Table 9 illustrates the very small aftereffect of pointing at a visual target with the unexposed hand. This measure was not reliably affected by either independent variable (all $F$ ratios $<1.0$ ) and was only about $16 \%$ of the corresponding measure with the exposed hand and about $35 \%$ of the VS measure. As in the previous experiments, there is no evidence here that the aftereffect for the unexposed hand is a measure of VS, especially since VS is affected by the exposure condition $[F(1,56)=25.73, p<.001]$ whereas there is no such effect for the unexposed hand measure. Again, the similar low levels of adaptation and the absence of effects for the TN, PN, and HS measures suggest that the TN measure is sensitive to changes in felt head position.

\section{CONCLUSIONS}

The present experiments firmly establish the reliability of effects of terminal and concurrent exposure on the relative magnitude of visual and proprioceptive adapta-

Table 8

Level of Adaptation (in Degrees) and 95\% Confidence Limits for Pointing Without Vision With the Exposed Hand and the Unexposed Hand and for the Head Shift Test as a Function of Combinations of Left or Right Hand Exposed and Terminal or Concurrent Exposure (Experiment 3)

\begin{tabular}{|c|c|c|c|c|c|c|c|}
\hline \multirow[b]{3}{*}{ Test } & \multirow[b]{3}{*}{ Exposure } & \multicolumn{4}{|c|}{ Hand } & \multirow{2}{*}{\multicolumn{2}{|c|}{$M$}} \\
\hline & & \multicolumn{2}{|c|}{ Left } & \multicolumn{2}{|c|}{ Right } & & \\
\hline & & LA & CL & LA & CL & LA & $\mathrm{CL}$ \\
\hline Exposed Hand (PS) & $\begin{array}{l}\mathrm{T} \\
\mathrm{C} \\
M\end{array}$ & $\begin{array}{l}1.7 \\
2.7 \\
2.2\end{array}$ & $\begin{array}{l}0.9 \\
1.1 \\
0.7\end{array}$ & $\begin{array}{l}1.3 \\
2.8 \\
2.1\end{array}$ & $\begin{array}{l}0.5 \\
1.5 \\
0.8\end{array}$ & $\begin{array}{l}1.5 \\
2.8 \\
2.2\end{array}$ & $\begin{array}{l}0.5 \\
0.8 \\
0.5\end{array}$ \\
\hline Unexposed Hand (PN) & $\begin{array}{l}\mathrm{T} \\
\mathrm{C} \\
\mathrm{M}\end{array}$ & $\begin{array}{r}0.6 \\
-0.1 \\
0.2\end{array}$ & $\begin{array}{l}0.4 \\
0.5 \\
0.3\end{array}$ & $\begin{array}{l}0.5 \\
0.5 \\
0.5\end{array}$ & $\begin{array}{l}0.3 \\
0.4 \\
0.2\end{array}$ & $\begin{array}{l}0.6 \\
0.2 \\
0.4\end{array}$ & $\begin{array}{l}0.2 \\
0.3 \\
0.2\end{array}$ \\
\hline HS & $\begin{array}{l}\mathbf{T} \\
\mathbf{C} \\
\mathbf{M}\end{array}$ & $\begin{array}{l}0.4 \\
0.4 \\
0.4\end{array}$ & $\begin{array}{l}0.2 \\
0.3 \\
0.2\end{array}$ & $\begin{array}{l}0.2 \\
0.2 \\
0.2\end{array}$ & $\begin{array}{l}0.2 \\
0.3 \\
0.2\end{array}$ & $\begin{array}{l}0.3 \\
0.3 \\
0.3\end{array}$ & $\begin{array}{l}0.2 \\
0.2 \\
0.2\end{array}$ \\
\hline
\end{tabular}

Note-LA = level of adaptation, $\mathrm{CL}=$ confidence limits, PS = proprioceptive shift, PN = proprioceptive shift with nonexposed hand, HS $=$ head shift, $\mathrm{T}=$ terminal, $\mathrm{C}=$ concurrent.

Table 9

Level of Adaptation (in Degrees) and 95\% Confidence Limits for the Visual Shift Test and for Target Pointing With the Unexposed Hand and Exposed Hand as a Function of Combinations of Left or Right Hand Exposed and Terminal or Concurrent Exposure (Experiment 3)

\begin{tabular}{|c|c|c|c|c|c|c|c|}
\hline \multirow[b]{3}{*}{ Test } & \multirow[b]{3}{*}{ Exposure } & \multicolumn{4}{|c|}{ Hand } & \multirow{2}{*}{\multicolumn{2}{|c|}{$M$}} \\
\hline & & \multicolumn{2}{|c|}{ Left } & \multicolumn{2}{|c|}{ Right } & & \\
\hline & & $\overline{\mathbf{L A}}$ & $\overline{C L}$ & $\mathbf{L A}$ & $\mathbf{C L}$ & $\mathbf{L A}$ & $\mathrm{CL}$ \\
\hline VS & $\begin{array}{l}\mathrm{T} \\
\mathbf{C} \\
\mathbf{M}\end{array}$ & $\begin{array}{l}2.4 \\
0.8 \\
1.6\end{array}$ & $\begin{array}{l}0.9 \\
0.4 \\
0.6\end{array}$ & $\begin{array}{l}2.9 \\
0.6 \\
1.8\end{array}$ & $\begin{array}{l}0.9 \\
1.0 \\
0.8\end{array}$ & $\begin{array}{l}2.6 \\
0.7 \\
1.7\end{array}$ & $\begin{array}{l}0.6 \\
0.5 \\
0.5\end{array}$ \\
\hline Unexposed Hand (TN) & $\begin{array}{l}\mathrm{T} \\
\mathrm{C} \\
\mathrm{M}\end{array}$ & $\begin{array}{l}0.8 \\
0.4 \\
0.6\end{array}$ & $\begin{array}{l}0.6 \\
1.3 \\
0.7\end{array}$ & $\begin{array}{l}0.9 \\
0.5 \\
0.7\end{array}$ & $\begin{array}{l}0.5 \\
0.6 \\
0.4\end{array}$ & $\begin{array}{l}0.8 \\
0.4 \\
0.6\end{array}$ & $\begin{array}{l}0.4 \\
0.7 \\
0.4\end{array}$ \\
\hline Exposed Hand (TS) & $\begin{array}{l}\mathrm{T} \\
\mathrm{C} \\
\mathrm{M}\end{array}$ & $\begin{array}{l}4.1 \\
3.5 \\
3.8\end{array}$ & $\begin{array}{l}1.1 \\
1.2 \\
0.8\end{array}$ & $\begin{array}{l}3.9 \\
3.3 \\
3.6\end{array}$ & $\begin{array}{l}1.3 \\
1.5 \\
1.0\end{array}$ & $\begin{array}{l}4.0 \\
3.4 \\
3.7\end{array}$ & $\begin{array}{l}0.8 \\
0.9 \\
0.9\end{array}$ \\
\hline
\end{tabular}

Note-LA $=$ level of adaptation, $\mathrm{CL}=$ confidence limits, VS $=$ visual shift, TN $=$ total shift with nonexposed hand, TS $=$ total shift, $\mathrm{T}=$ terminal, $\mathrm{C}=$ concurrent. 
tion, and the applicability of the linear model to these exposure conditions. Visual adaptation is greater with terminal exposure and proprioceptive adaptation is greater with concurrent exposure, but regardless of exposure condition, visual and proprioceptive adaptation sum to equal the total adaptation in the eye-hand control loop.

These terminal versus concurrent exposure effects occurred with or without exposure targets (Experiment 1) and whether the left or right hand was exposed (Experiment 3). Moreover, these results were established for aftereffect measures and under conditions that are unlikely to have produced asymmetric eye posture. Thus, conscious correction or eye-muscle potentiation aftereffects do not seem to be involved. The only condition under which terminal exposure did not produce greater visual shift was the unconstrained head-movement condition. It may be that this result arose from an asymmetric head posture with consequent reduction in the stimulus (discordance) for visual adaptation and addition of head shift to the measure of proprioceptive adaptation.

The only exception to additivity in these experiments occurred when targets were present (Experiment 1). It seems likely that the obtained overadditivity arose from assimilation of an error-corrective motor response that is encouraged by the presence of targets.

Thus, the eye-hand coordination loop can be viewed as a serial linkage of component eye-head and hand-head systems, and the locus of adaptation may be determined by the direction of the coordinative linkage between subsystems (Redding et al., 1985). In terminal exposure, subjects may depend upon proprioception to guide the pointing hand and eyes, and the discordance between visual and proprioceptive systems is registered in the guided visual system, with consequent perceptual recalibration of encoding operators in the visual system. In concurrent exposure, subjects may depend upon vision to guide the hand and eyes, and the locus of discordance registration and adaptation is in the guided proprioceptive system. Further work to test this conceptualization is in progress, including controls for the differences in hand movements between the two exposure conditions and manipulation of extent of the movement path through which the hand is visible.

The exceedingly small amounts of intermanual transfer found when the head was fixed (Experiments 1 and 3) suggest that there is little if any direct transfer from exposed to nonexposed hands. The little transfer that occurred seems to have been due to aftereffects of asymmetric head posture. This conclusion is supported by the fact that intermanual transfer was largest when the head was permitted to move during exposure (Experiment 2), and by the similarity between intermanual transfer measures and direct measures of HS (Experiments 2 and 3). It seems likely that the magnitude of intermanual transfer measures would be even more similar to measures of HS if, during test, the head were permitted less constrained movement about the spinal axis of rotation.
Target pointing transfer with the unexposed hand remains problematical. Clearly, such transfer is not simply a measure of visual adaptation, since in all three experiments the terminal/concurrent exposure manipulation affected the direct measure of visual adaptation (VS) but never the transfer measure. The only factor affecting the transfer measure was the head-movement manipulation (Experiment 2): greater head movement during exposure produced more target pointing transfer. Thus, in these experiments, this transfer measure appears to have been sensitive to changes in felt head position, but not to visual adaptation. These results suggest that the eye-hand coordinative linkages may be unique for the two hands, with different encoding operators translating between visual space and the left- and right-hand proprioceptive spaces. Such an organization of the perceptual-motor system would explain the dissimilarity between visual shift and transfer measures in the present experiments, but such theorizing must be considered speculative at the present time.

\section{REFERENCES}

CHOE, C. S., \& WELCH, R. B. (1974). Variables affecting the intermanual transfer and decay of prism adaptation. Journal of Experimental Psychology, 102, 1076-1084.

Cohen, M. M. (1967). Continuous versus terminal visual feedback in prism aftereffects. Perceptual \& Motor Skills, 24, 1295-1302.

Craske, B. (1975). A current view of the processes and mechanisms of prism adaptation. Les Colloques de ITnstitut National de la Santé et de la Recherche Médicale, 43, 125-138.

Crawshaw, M., \& Craske, B. (1974). No retinal component in prism adaptation. Acta Psychologica, 38, 421-423.

Ebenholtz, S. M. (1974). The possible role of eye-muscle potentiation in several forms of prism adaptation. Perception, 3, 477-485.

EBENHOLTZ, S. M. (1976). Additivity of aftereffects of maintained head and eye rotations: An altemative to recalibration. Perception \& Psychophysics, 76, 113-116.

Ebenholtz, S. M., Fisher, S. K. (1982). Distance adaptation depends upon plasticity in the oculomotor control system. Perception \& Psychophysics, 31, 551-560.

Freedman, S. J. (1968). Perceptual compensation and learning. In S. J. Freedman (Ed.), The neuropsychology of spatially oriented behavior. Homewood, IL: Dorsey.

HAMilton, C. R. (1964). Studies on adaptation to deflection of the visual field in split-brain monkeys and man. Unpublished doctoral dissertation, California Institute of Technology, Pasadena.

Harris, C. S. (1974). Beware of the straight-ahead shift: A nonperceptual change in experiments on adaptation to displaced vision. Perception, 3, 461-476.

HaRris, C. S. (1980). Insight or out of sight? Two examples of perceptual plasticity in the human adult. In C. S. Harris (Ed.), Visual coding and adaptability. Hillsdale, NJ: Erlbaum.

HAY, J. C., \& PiCK, H. L., JR. (1966). Visual and proprioceptive adaptation to optical displacement of the visual stimulus. Joumal of Experimental Psychology, 71, 150-158.

HeLD, R., \& Bossom, J. (1961). Neonatal deprivation and adult rearrangement: Complementary techniques for analyzing plastic sensorymotor coordinations. Journal of Comparative \& Physiological Psychology, 54, 33-37.

Helmholtz, H. von. (1925). Treatise on physiological optics (Vol. 3). Rochester, NY: Optical Society of America.

HowARD, I. P. (1971). Perceptual learning and adaptation. British Medical Bulletin, 27, 248-252.

Howard, I. P. (1982). Human visual orientation. New York: Wiley. 
HowARD, I. P., \& ANSTIS, T. (1974). Muscular and joint-receptor components in postural persistence. Journal of Experimental Psychology, $103,167-170$.

Howard, I. P., Templeton, W. B. (1966). Human spatial orientation. New York: Wiley.

Redding, G. M. (1978). Additivity in adaptation to optical tilt. Journal of Experimental Psychology: Human Perception \& Performance, 4, 178-190.

Redding, G. M., Clark, S. E., \& Wallace, B. (1985). Attention and prism adaptation. Cognitive Psychology, 17, 1-25.

Redding, G. M., \& WallaCe, B. (1976). Components of displacement adaptation in acquisition and decay as a function of hand and hall exposure. Perception \& Psychophysics, 20, 453-459.

RedDing, G. M., Wallace, B. (1978). Sources of "overadditivity" in prism adaptation. Perception \& Psychophysics, 24, 58-62.

Redding, G. M., \& Wallace, B. (1985a). Cognitive interference in prism adaptation. Perception \& Psychophysics, 37, 225-230.

Redding, G. M., Wallace, B. (1985b). Perceptual-motor coordination and adaptation during locomotion: Determinants of prism adaptation in hall exposure. Perception \& Psychophysics, 38, 320-330.

RedDing, G. M., \& Wallace, B. (1987). Perceptual-motor coordination and adaptation during locomotion: A control for head posture contributions. Perception \& Psychophysics, 42, 269-274.

RoBINSON, D. A. (1976). Adaptive gain control of vestibuloocular reflex by the cerebellum. Journal of Neuropsychology, 39, 954-969.

Stratton, G. M. (1896). Some preliminary experiments on vision without inversion of the retinal image. Psychological Review, 3 , 611-617.

Templeton, W. B., Howard, I. P., \& Wilkinson, D. A. (1974). Additivity of components of prismatic adaptation. Perception \& Psychophysics, 15, 249-257.

UHLARIK, J. J., \& CANON, L. K. (1971). Influence of concurrent and terminal exposure conditions on the nature of perceptual adaptation. Journal of Experimental Psychology, 9, 233-239.

Wallace, B. (1974). Preexposure pointing frequency effects on adaptation to prismatic viewing. Perception \& Psychophysics, 15, 26-30.

WALLACE, B. (1977). Stability of Wilkinson's linear model of prism adaptation over time for various targets. Perception, 6, 145-151.

WALLACE, B. (1978). Visuomotor coordination and intermanual transfer for a proprioceptive reaching task. Joumal of Motor Behavior, 10, 139-147.

WALLACE, B., \& ReDDING, G. M. (1979). Additivity in prism adaptation as manifested in intermanual and interocular transfer. Perception \& Psychophysics, 25, 133-136.
WELCH, R. B. (1974). Research on adaptation to rearranged vision: $1966-$ 1974. Perception, 3, 367-392.

Welch, R. B. (1978). Perceptual modification. New York: Academic Press.

Welch, R. B., Choe, C. S., \& Heinrich, D. R. (1974). Evidence for a three-component model of prism adaptation. Joumal of Experimental Psychology, 103, 700-705.

WiLkInson, D. A. (1971). Visual-motor control loop: A linear system? Journal of Experimental Psychology, 89, 250-257.

\section{NOTES}

1. The term visual adaptation is used to designate adaptive change in the eye-head system that has phenomenal consequences for visual perception. The basic nature of such adaptation may be a change in either retinal local sign or registered eye position (e.g., Crawshaw \& Craske, 1974; Harris, 1980). Current theory does not permit a test between these two possible accounts of visual change, and the present research is neutral with respect to this problem. Proprioceptive adaptation refers to any change in felt position of body parts. In the present study, the tests are sensitive to any such proprioceptive shift between hand and head.

2. The term perceptual recalibration is reserved for calibration processes that determine the deviation of one sensorimotor system (e.g., eye-head) from the (external) standard provided by another (discordant) system so as to ascertain the proper correction factors. Muscle potentiation effects (Ebenholtz, 1974) or joint-receptor adaptation (Howard \& Anstis, 1974) do not involve any reference to an external standard, but simply arise from a shift in a muscle group's or a joint receptor's resting position produced by atypical exercise. Both perceptual recalibration and postural aftereffects have perceptual consequences, and both are assumed to be localized within a sensorimotor system, but the underlying mechanisms are different in nature. Recalibration requires input from an external discordant system, whereas postural aftereffects do not.

3. It might be argued that subjects could fixate a position in the field far enough from the target position or field center in the direction of the displacement that when they pointed in the direction of this visual gaze the error would be eliminated. Of course, if this were to happen the eyes would be asymmetrically exercised. However, this would be an unlikely occurrence, since it would require development of a complex strategy within less than about four trials (about $12 \mathrm{sec}$ ).

(Manuscript received March 30, 1987; revision accepted for publication December 14, 1987.) 